УДК 338.2

$10.17213 / 2075-2067-2021-1-178-187$

\title{
ИНДИВИДУАЛЬНОЕ ПРЕДПРИНИМАТЕЛЬСТВО В РЕГИОНАЛЬНОМ ЭКОНОМИЧЕСКОМ РАЗВИТИИ
}

\author{
(C) 2021 г. H. A. Пемухов
}

\section{Институт проблем управления РАН, г. Москва, Россия}

Целью исследования является анализ и оченка состояния предпринимательства в регионах Российской Федеращии, анализ перспектив развития индивидуального предпринимательства.

Методологическую базу исследования представляют работы современных экономистов в области предпринимательства и региональной экономики, методы статистического анализа.

Результаты исследования. Проведена оценка современного состояния предпринимательства в российских регионах, особенности занятости населения на неформальном рынке труда; определены региональные зависимости между уровнем занятых в сфере индивидуального предпринимательства и уровнем ВРП, плотностью населения в регионе, долей городского населения; проведен анализ возрастной структуры занятых в сфере индивидуального предпринимательства и неформальном рынке труда.

Перспектива исследования состоит в дальнейшем развитии индивидуального предпринимательства, как средства получения основного и дополнительного дохода, особенно в кризисных ситуациях; разработке мер по сокращению неформального рынка труда, применению различных форм самозанятости.

Ключевые слова: индивидуальное предпринимательство; доля занятых в сфере индивидуального предпринимательства; трудоспособное население; самозанятость; неформальный рынок труда.

\section{INDIVIDUAL ENTREPRENEURSHIP IN REGIONAL ECONOMIC DEVELOPMENT}

\section{(C) 2021 N. A. Petukhov}

\section{Institute of Control Sciences, Russian Academy of Sciences, Moscow, Russia}

The purpose of the research is to analyze and assess the state of entrepreneurship in the regions of the Russian Federation, to analyze the prospects for the development of individual entrepreneurship.

The methodological basis of the research is represented by the works of modern economists in the field of entrepreneurship and regional economics, methods of statistical analysis.

Research results. The assessment of the current state of entrepreneurship in the Russian regions, the specifics of employment of the population in the informal labor market; the regional dependences between the level of employed in the field of individual entrepreneurship and the level of GRP, the density of the population in the region, the share of the urban population are determined; the analysis of the age structure of those employed in the sphere of individual entrepreneurship and the informal labor market has been carried out. 
The research perspective is consists in the further development of individual entrepreneurship as a means of obtaining both main and additional income, especially in crisis situations; development of measures to reduce the informal labor market, the use of various forms of selfemployment.

Key words: individual entrepreneurship; share of those employed in the field of individual entrepreneurship; able-bodied population; self-employment; informal labor market.

Развитие экономики подразумевает развитие предприятий различных отраслей, выпускающих продукцию, оказывающих услуги, выполняющих работы. Отраслевая структура предприятий в регионах Российской Федерации различна в связи с особенностями регионов; но в большинстве случаев можно выделить несколько основных отраслей, которые, как правило, в различной степени присутствуют практически во всех регионах Российской Федерации (обрабатывающие производства, сельское хозяйство, оптовая и розничная торговля и т.п.). Вместе с тем существуют определенные проблемы в размещении предприятий на территории региона, которые связаны с особенностями функционирования таких предприятий — наличие рынка сбыта, наличие трудовых и других ресурсов. Такое неравномерное распределение предприятий, а также различная степень охвата населения услугами, прежде всего, в небольших населенных пунктах, являются одной из причин развития предпринимательства, в особенности малого.

Но помимо малых и микропредприятий, на рынке присутствуют и индивидуальные предприниматели без образования юридического лица. К особенностям работы индивидуального предпринимателя можно отнести упрощенный вариант открытия, работы и налогообложения по сравнению с обычными предприятиями - юридическими лицами. Предпринимательство в статусе индивидуального предпринимателя является одним из вариантов получения дохода, а также одной из форм занятости населения.

Помимо работы в статусе индивидуального предпринимателя (или открытия предприятия в статусе юридического лица), существуют и другие, аналогичные формы занятости населения, подпадающие под понятие «неформальный сектор» занятости населения. Росстат определяет неформаль- ный сектор по отсутствию регистрации юридического лица, занятыми в котором будут индивидуальные предприниматели, лица, работающие по найму у индивидуальных предпринимателей, помогающие члены семьи, работающие на индивидуальной основе без регистрации в качестве индивидуального предпринимателя, занятые в домашнем хозяйстве производством продукции сельского и лесного хозяйства, охоты и рыболовства.

По своей сути, индивидуальные предприниматели и лица, работающие по найму у индивидуального предпринимателя, участвуют в экономическом процессе наравне с предприятиями, имеющими статус юридического лица, и работниками таких предприятий, могут осуществлять аналогичную деятельность с извлечением прибыли, но имеют некоторые упрощения в организации своей деятельности. Так же можно сравнить крестьянские (фермерские) хозяйства с сельскохозяйственными предприятиями.

В большей степени к неформальному рынку занятости будут относиться те лица, которые осуществляют свою деятельность без регистрации (неважно, в каком статусе), получающие доход от такой деятельности (или находящиеся на иждивении у нанимателя). К причинам существования неформального рынка труда можно отнести уход от налогов, снижение затрат (на лицензирование, получение разрешений) с целью получения несколько большей прибыли. Но на сегодняшний день с 1 января 2019 года Правительством Российской Федерации вводится новый статус (пока еще в форме эксперимента с последующим расширением количества регионов, его применяющих) - «самозанятость», который позволяет контролировать часть неформального рынка и имеет несколько упрощенный вариант открытия и работы по сравнению с индивидуальным предпринимательством. 
Даже с возможностью осуществлять предпринимательскую деятельность как «самозанятый» все равно часть таких людей останется работать в неформальном секторе, т.к. могут существовать различные причины, по которым невыгодно регистрировать свою деятельность, например: если выполняемые работы или услуги носят разовый, нерегулярный характер; для выполнения работ необходимо получить разрешение или лицензию, но существуют определенные ограничения или правила (например, наличие определенного образования или опыта работы); для некоторых лиц данная занятость является приработком по основному месту деятельности; осуществляется работа на семейном предприятии и т.п. Также, пока регистрация в качестве самозанятого носит экспериментальный характер, существуют определенные проблемы по поводу ставки налогов, отчисления в социальные фонды и дальнейших перспектив налогообложения и правил работы, часть лиц неформального сектора не торопится регистрироваться в статусе самозанятого.

В 2019 году, по данным Росстата, из общего количества занятых, в неформальном секторе (по определению Росстата - предпринимательство без образования юридического лица, в состав которого входят и индивидуальные предприниматели и лица, работающие по найму в ИП) работает порядка 20,58 \% [1]. Но без учета самих занятых в сфере индивидуального предпринимательства (таких лиц 9,42\% от общей численности занятых) неформальный сектор, по оценке Росстата, составляет $11,16 \%$ от общей численности занятых в экономике (табл. 1).
О важности развития индивидуального предпринимательства говорит и тот факт, что в 2018 году, по данным Росстата, в Российской Федерации насчитывалось 4214,7 тыс. предприятий, 238,3 тыс. малых предприятий (без учета микропредприятий), оборот предприятий составил 191820,6 млрд. руб., оборот малых предприятий (без учета микропредприятий) — 29425,7 млрд. руб. А численность индивидуальных предпринимателей в аналогичном периоде составила 2630,8 тыс. человек, выручка 15003,8 млрд. руб. На малых предприятиях (без учета микропредприятий) работало 5800,6 тыс. человек, на ИП - 5976,7 тыс. человек. Численность индивидуальных предпринимателей в 2018 году превышает общее количество предприятий, их выручка приблизительно в два раза меньше оборота малых предприятий, но в сфере индивидуального предпринимательства работает почти столько же человек, сколько и на малых предприятиях [2].

Также к особенностям индивидуального предпринимательства можно отнести то, что в ИП работает один предприниматель и в зависимости от особенностей своей работы он может нанимать на работу еще несколько человек; по сравнению с предприятиями, имея небольшие затраты на производство товаров и оказание услуг, индивидуальный предприниматель может работать на небольших рынках сбыта (в небольших населенных пунктах), где работать предприятиям - юридическим лицам - может быть невыгодно. Индивидуальные предприниматели вследствие своей гибкости занимают определенные ниши рынка, тем самым дополняя его и предлагая то-

Таблица 1

\section{Занятые в экономике Российской Федерации (по данным Росстата в 2019 году), тыс. чел.}

\begin{tabular}{|l|c|c|}
\hline & тыс. чел. & $\begin{array}{c}\text { в \% } \\
\text { от занятых }\end{array}$ \\
\hline Рабочая сила & 75397,9 & \\
\hline Занятые & 71933,1 & 100 \\
\hline Неформальный сектор & 14800,3 & 20,58 \\
\hline Численность индивидуальных предпринимателей & 2738,6 & \\
\hline Численность занятых в сфере индивидуального предпринимательства & 6774,9 & 9,42 \\
\hline
\end{tabular}


вары и услуги, которые по разным причинам на таком рынке могут отсутствовать.

Индивидуальное предпринимательство, так же, как и другие формы неформальной занятости, являются способом получения дохода, как основного, так и дополнительного, влияют на ситуацию на рынке труда, решают проблему занятости, предоставляют доступ к товарам и услугам, в силу различных причин отсутствующих на локальном рынке. В некоторых случаях, как индивидуальный предприниматель, так и неформальный сектор занятости может составлять высокую конкуренцию действующим предприятиям (например, репетиторство, подготовка к сдаче ЕГЭ).

Развитие предпринимательства, особенно в сельской местности, будет также решать проблему развития территорий. Так, по данным сельскохозяйственной переписи 2016 года [3], число сельскохозяйственных предприятий в Российской Федерации на 1 июля 2016 года составило 36048 предприятий (в том числе малых предприятий — 24284), крестьянских (фермерс- ких) хозяйств - 174765 (в том числе индивидуальных предпринимателей - 38046). В 2015 году среднегодовая численность работников сельскохозяйственных предприятий составила 1323958 человек (в том числе малых предприятий - 353505 человек), крестьянских (фермерских) хозяйств - 300848 человек (в том числе индивидуальных предпринимателей - 60524 человек).

Рассматривая возрастную структуру занятых в неформальном секторе (с позиции Росстата) в 2019 году, обнаруживаем, что в разных возрастных группах доля занятых в неформальном секторе в среднем находится на уровне около 20\%; причем, начиная с возрастной группы 20-24 года, происходит уменьшение такой доли с увеличением возраста до 60-64 лет. А в возрастных группах 15-19, 65-69 и старше 70 доля занятых в неформальном секторе от общей численности занятых выше среднего значения для остальных возрастных групп (табл. 2).

C позиции Росстата, в неформальный сектор входят не только индивидуальные предприниматели, но и помогающие члены

Таблица 2

Возрастная структура рабочей силы и занятых в Российской Федерации в 2019 году

\begin{tabular}{|c|c|c|c|c|c|c|}
\hline & $\begin{array}{c}\text { Рабочая } \\
\text { сила, } \\
\text { тыс. чел. }\end{array}$ & $\begin{array}{c}\text { Занятые, } \\
\text { тыс. чел. }\end{array}$ & $\begin{array}{c}\text { Занятые, } \\
\text { в \% от } \\
\text { рабочей } \\
\text { силы }\end{array}$ & $\begin{array}{c}\text { Занятые в } \\
\text { неформальном } \\
\text { секторе, } \\
\text { тыс. чел. }\end{array}$ & $\begin{array}{c}\text { Занятые в } \\
\text { неформальном } \\
\text { секторе, } \\
\text { в от занятых }\end{array}$ & $\begin{array}{c}\text { Занятые в } \\
\text { неформальном } \\
\text { векторе, } \\
\text { в к итогу }\end{array}$ \\
\hline Всего & 75398 & 71933 & 95,4 & 14800 & 20,57 & 100 \\
\hline \multicolumn{6}{|l|}{} & \multicolumn{5}{l|}{} \\
\hline $15-19$ & 466 & 350 & 75,11 & 168 & 48 & 1,14 \\
\hline $20-24$ & 4234 & 3623 & 85,57 & 955 & 26,36 & 6,45 \\
\hline $25-29$ & 9849 & 9293 & 94,35 & 1987 & 21,38 & 13,43 \\
\hline $30-34$ & 11487 & 10987 & 95,65 & 2315 & 21,07 & 15,64 \\
\hline $35-39$ & 10488 & 10108 & 96,38 & 2116 & 20,93 & 14,3 \\
\hline $40-44$ & 9701 & 9369 & 96,58 & 1911 & 20,4 & 12,91 \\
\hline $45-49$ & 8791 & 8481 & 96,47 & 1656 & 19,53 & 11,19 \\
\hline $50-54$ & 8288 & 7984 & 96,33 & 1501 & 18,8 & 10,14 \\
\hline $55-59$ & 7397 & 7161 & 96,81 & 1243 & 17,36 & 8,4 \\
\hline $60-64$ & 3243 & 3166 & 97,63 & 566 & 17,88 & 3,82 \\
\hline $65-69$ & 1119 & 1085 & 96,96 & 253 & 23,32 & 1,71 \\
\hline 70 и & 336 & 328 & 97,62 & 129 & 39,33 & 0,87 \\
\hline старше & & & & & \\
\hline
\end{tabular}


семей, лица, занятые в домашнем хозяйстве; и вполне логично предположить, что в большинстве случаев к ним будут относиться лица моложе 20 лет, большинство которых, как правило, еще проходят обучение или в школе, или в различных образовательных учреждениях, а также лица пенсионного возраста. Лица пенсионного возраста и старше 60 лет помимо такой помощи и занятий домашним хозяйством (работа на дачном участке и т.п.), имея определенную квалификацию и опыт работы, также могут заниматься и другими видами деятельности, которая относится к неформальному сектору, быть «самозанятыми» (репетиторство, помощь по дому, уход за детьми и престарелыми и т.п.).

Рассматривая возрастную структуру занятых в неформальном секторе в 2019 году, можно сказать, что большая часть приходится на лица в возрасте 30-34 года (более 15\% от общей численности занятых в неформальном секторе), а на долю каждой из возрастных групп 25-29, 35-39, 40-44, 45-49, 50-54 лет приходится порядка 10-15\% от общей численности занятых в неформальном секторе. Менее двух процентов приходится на каждую из возрастных групп 15-19, 65-69 и старше 70 лет.
По методике Росстата, в неформальный сектор входят и индивидуальные предприниматели (т.к. не имеют статуса юридического лица), хотя они имеют государственную регистрацию, платят налоги и осуществляют коммерческую деятельность наравне с юридическими лицами, только с некоторыми упрощениями в своей деятельности. С учетом того, что в неформальном секторе занятых в индивидуальном предпринимательстве менее половины, а количество индивидуальных предпринимателей еще меньше, то получается, что доля индивидуальных предпринимателей в общей численности работников неформального сектора в среднем находится на уровне $5-8 \%$.

Возрастная структура лиц, занимающихся предпринимательской деятельностью, по данным выборочного исследования Росстата в 2017-2018 гг., дана в табл. 3. От общей численности индивидуальных предпринимателей наибольшие доли приходятся на лиц возрастных групп 30-34, 35-39, 40-44, 45-49 и 50-54 года (более чем $12 \%$ на каждую группу).

Возрастная структура занятых в индивидуальном предпринимательстве будет несколько отличаться от структуры неформаль-

Таблица 3

Распределение лиц, занимающихся предпринимательской деятельностью, по возрасту (по материалам выборочного исследования Росстата)

\begin{tabular}{|c|c|c|c|c|}
\hline \multirow{2}{*}{} & \multicolumn{2}{|c|}{2017} & \multicolumn{2}{c|}{2018} \\
\cline { 2 - 5 } & Тыс. человек & В \% к итогу & Тыс. человек & В \% к итогу \\
\hline Всего & 3511 & 100 & 3688 & 100 \\
\hline в том числе в возрасте, лет: & 29 & 0,8 & 51 & 1,4 \\
\hline до 20 & 153 & 4,4 & 139 & 3,8 \\
\hline $20-24$ & 361 & 10,3 & 361 & 9,8 \\
\hline $25-29$ & 455 & 12,9 & 502 & 13,6 \\
\hline $30-34$ & 501 & 14,3 & 522 & 14,2 \\
\hline $35-39$ & 514 & 14,6 & 518 & 14 \\
\hline $40-44$ & 470 & 13,4 & 473 & 12,8 \\
\hline $45-49$ & 466 & 13,3 & 451 & 12,2 \\
\hline $50-54$ & 343 & 9,8 & 370 & 10 \\
\hline $55-59$ & 194 & 5,5 & 254 & 6,9 \\
\hline $60-69$ & 26 & 0,7 & 46 & 1,3 \\
\hline 70 и старше & & & \\
\hline
\end{tabular}


ного рынка труда, но в целом имеет схожие тенденции. Основная масса предпринимателей — это лица старше 30 лет, к этому возрасту уже происходит получение специального образования и накопление первоначального опыта практической работы, что позволяет применять полученные знания для занятия предпринимательством. На неформальном рынке труда также большая часть занятых старше 30 лет и имеет определенное образование и опыт работы.

В 2019 году по сравнению с 2018 годом произошло увеличение численности индивидуальных предпринимателей на 4,1\%, занятых в сфере индивидуального предпринимательства - на 13,4\%, но общая численность занятых в неформальном секторе (по определению Росстата) увеличилась всего лишь на 1,5\% по сравнению с 2018 годом. Также с учетом того, что вводится новый статус «самозанятый», такое изменение говорит о том, что на рынке труда все большее число лиц начинает регистрировать свою деятельность и производить продукцию, оказывать услуги, выполнять работы на законных основаниях.
На сегодняшний день доля занятых в сфере индивидуального предпринимательства среди трудоспособного населения в некоторых регионах составляет более $10-15 \%$. В среднем в большинстве регионов порядка 7-11\% от общей численности трудоспособного населения работают в сфере индивидуального предпринимательства — как в статусе индивидуального предпринимателя, так и в виде наемных работников в ИП.

В 2019 году наибольшая доля занятых в сфере ИП была в Республике Бурятия (18,3\% от общей численности трудоспособного населения), Республике Хакасия (15,2\%), Республике Крым (14,0\%). Наименьшая доля была в Республике Дагестан (3,6\%), Мурманской области (5,3\%), Кабардино-Балкарской Республике $(5,5 \%)$. В последние годы одни из наибольших значений доли занятых в сфере индивидуального предпринимательства среди трудоспособного населения имеют такие российские регионы, как Республика Бурятия, Республика Хакасия, Республика Крым, Республика Тыва, Сахалинская область; одни из наименьших значений ежегод-

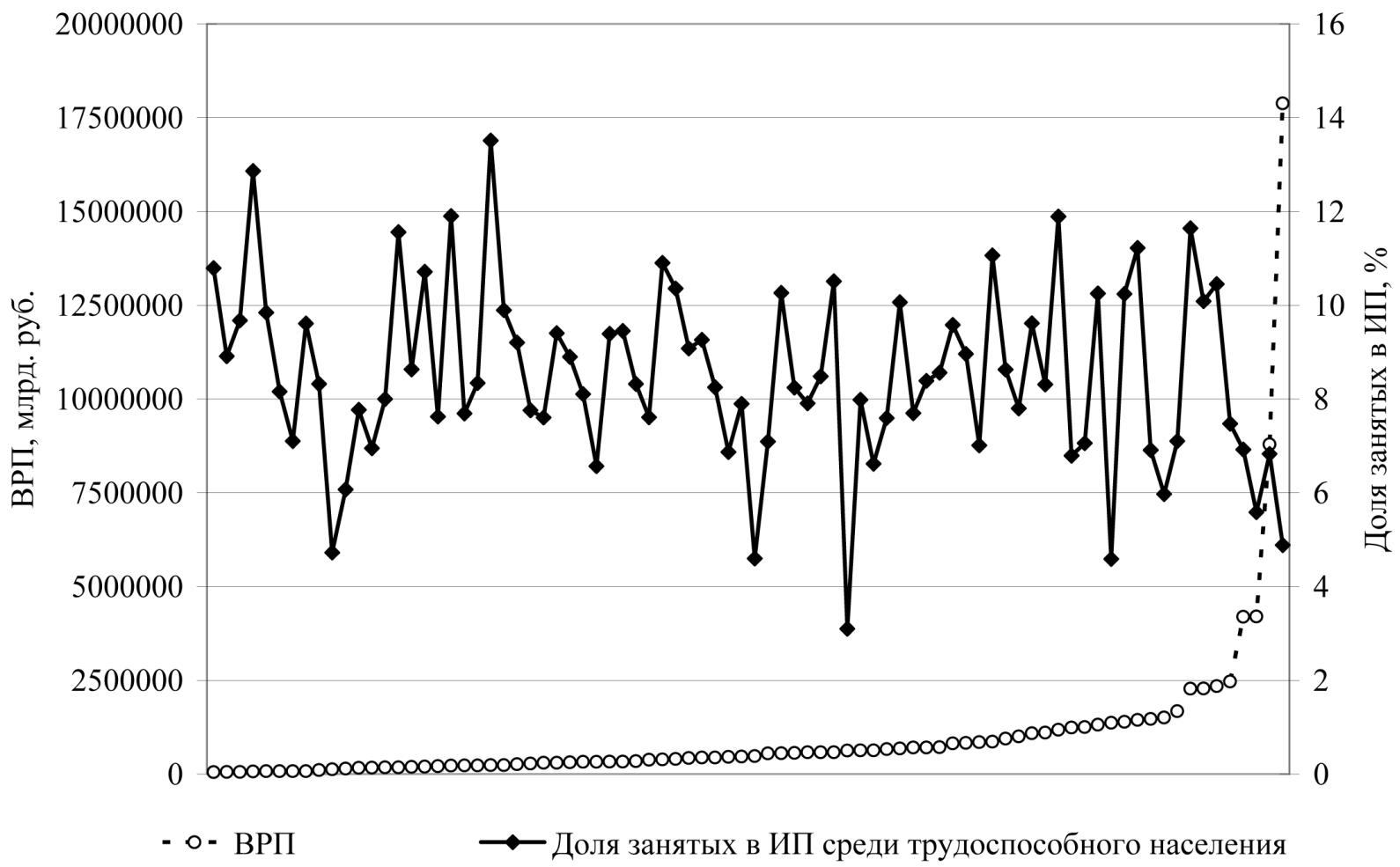

Рис. 1. Доля занятых в сфере индивидуального предпринимательства среди трудоспособного населения в регионах Российской Федерации с различными значениями ВРП в 2018 году 
но имеют Республика Дагестан, Мурманская область, Нижегородская область, г. Москва и Московская область.

Сравнивая размер валового регионального продукта как показателя экономического развития региона с долей занятых в сфере индивидуального предпринимательства среди трудоспособного населения в регионах Российской Федерации в 2018 году (рис. 1), можем сделать вывод о том, что в регионах с низким значением ВРП (ниже среднего) достаточно большое количество трудоспособного населения работает в сфере ИП.

Величина ВРП для большинства регионов в 2018 году не превышает 2000000 млрд. рублей, выше данного показателя ВРП только в восьми регионах. Для большинства регионов, особенно с величиной ВРП ниже среднего значения, важна роль индивидуального предпринимательства как правило, в большинстве случаев доля занятых в сфере ИП в таких регионах несколько выше. Но чем выше ВРП (особенно это заметно в регионах с наибольшими значениями ВРП), тем меньше населения трудится в сфере ИП. В основном в регионах с наибольшими значениями ВРП, таких как г. Москва и Московская область, г. СанктПетербург, Тюменская область, Республика Татарстан, Свердловская область и др., на рынке присутствует достаточно большое количество крупных предприятий различных отраслей, и доля индивидуального предпринимательства несколько ниже.

Территория Российской Федерации населена неравномерно, и в разных регионах доля городского населения различна. Для сельского населения необходимы определенные товары и услуги так же, как и для городского населения, но вследствие удаления от городов и малого количества населения в таких сельских населенных пунктах не всегда есть возможность приобретения товара или получения услуги. На сегодняшний день в сельской местности ниже уровень средних заработных плат и выше уровень безработицы. Для сельского населения одним из выходов из такой ситуации является предпринимательство - или открытие фермерского хозяйства, или оказание определенных востребованных услуг, отсутствующих на селе.

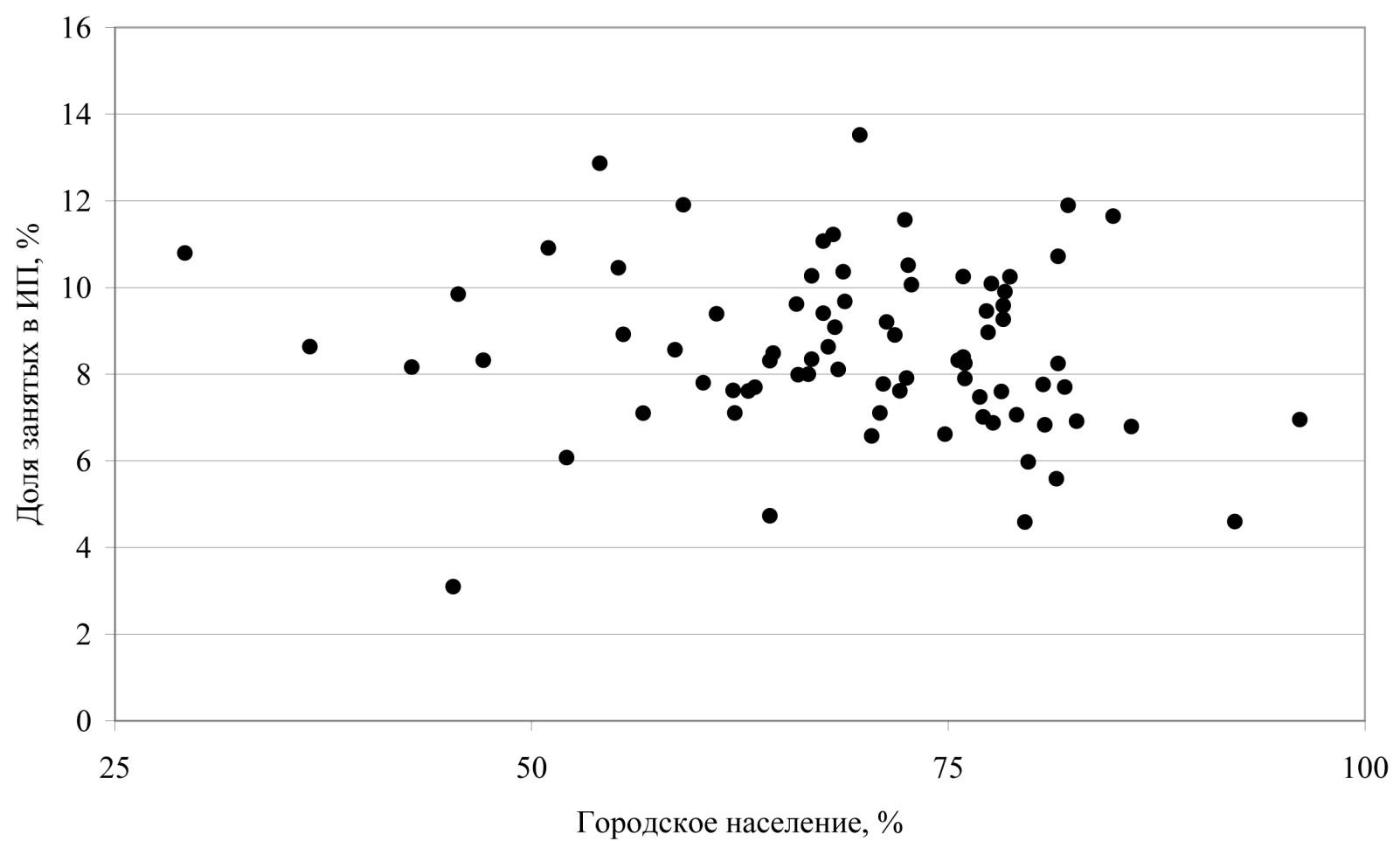

Рис. 2. Доля занятых в сфере индивидуального предпринимательства среди трудоспособного населения в регионах Российской Федерации с различной долей городского населения в 2018 году 


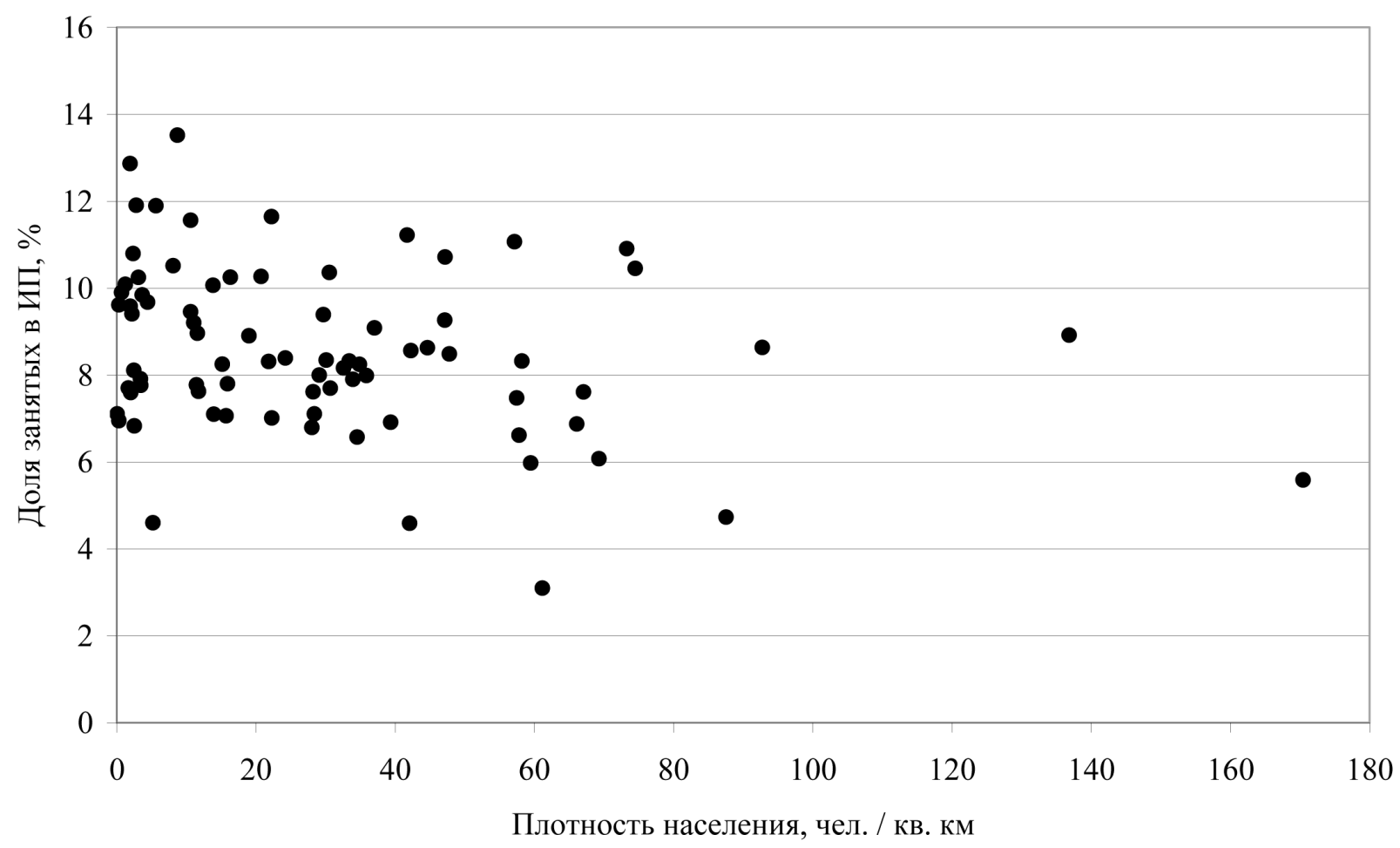

Рис. 3. Доля занятых в сфере индивидуального предпринимательства среди трудоспособного населения в регионах Российской Федерации с различной плотностью населения в 2018 году

В целом, рассматривая регионы Российской Федерации с позиции доли городского населения и доли трудоспособного населения, работающего в сфере индивидуального предпринимательства в 2018 году (рис. 2), можно обнаружить тенденцию к уменьшению доли занятых в сфере ИП в регионах с увеличением доли городского населения [4].

Для городов федерального значения г. Москва, г. Санкт-Петербург и г. Севастополь - доля занятых в сфере индивидуального предпринимательства среди трудоспособного населения в 2018 году составила 4,88\%, $6,92 \%$ и 9,61\% соответственно. Плотность населения в российских регионах будет различной, и в 2018 году за исключением трех городов федерального значения наибольшая плотность населения была в Московской области (170,46 человек на 1 км²), Республике

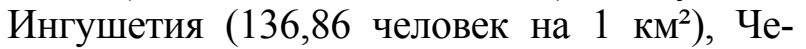

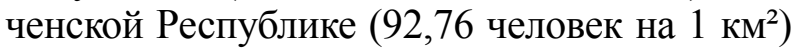
и Республике Северная Осетия-Алания $(87,56$ человек на $1 \mathrm{~km}^{2}$ ). В остальных регионах данный показатель не превышал 75 человек

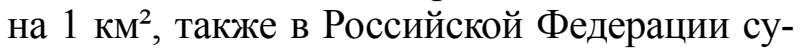

ществуют регионы с плотностью населения менее 5-10 человек на 1 км². $^{2}$

Как в случае с долей городского населения, так и в случае со сравнением доли занятых в сфере ИП среди трудоспособного населения с плотностью населения (рис. 3) просматривается тенденция к уменьшению доли занятых в сфере ИП с увеличением плотности населения в регионе.

В современных условиях существуют определенные проблемы занятости населения, особенно в сельской местности. Занятие индивидуальным предпринимательством является одним из способов не только занятости населения, но и получения дополнительного дохода населением. Получение такого дохода также может осуществляться в неформальном секторе занятости, в частности, посредством оказания различных услуг (например, репетиторства, частного извоза и т.п.) [5].

Государство должно всячески стимулировать развитие индивидуального предпринимательства, которое способствует развитию территорий, создает дополнительные рабочие места, развивает региональные рынки 
товаров и услуг, позволяет части населения трудоустроиться или заняться предпринимательством, например, в случаях отсутствия рабочих мест или наличия проблем с трудоустройством (особенно лиц предпенсионного возраста). В отличие от неформального сектора занятости индивидуальные предприниматели платят налоги в бюджет и внебюджетные фонды, и количество ИП ежегодно увеличивается больше, чем численность занятых в неформальном секторе. Индивидуальное предпринимательство является одним из факторов экономического развития, позволяющего также решать региональные проблемы.

\section{Литература}

1. Малое и среднее предпринимательство в России. 2019: Стат. сб. / Росстат. - М., 2019. $-87 \mathrm{c}$.

2. Рабочая сила, занятость и безработица в России (по результатам выборочных обследований рабочей силы). Стат. сб. / Росстат. M., $2020 .-145 \mathrm{c}$.

3. Итоги Всероссийской сельскохозяйственной переписи 2016 года: в 8 т. / Федеральная служба гос. статистики. - М.: ИИЦ «Статистика России», 2018.

4. Российский статистический ежегодник. 2019: Стат. сб. / Росстат. - М., 2019. $708 \mathrm{c}$.

5. Нижегородиев Р.М., Петухов Н.А. Подходы к прогнозированию спроса на региональных рынках труда // Управление ин- новациями - 2020: Материалы международной научно-практической конференции / Под ред. Р. М. Нижегородцева, Н.П. Горидько. Новочеркасск: ЮРГПУ (НПИ), 2020.

\section{References}

1. Maloe i srednee predprinimatel'stvo $\mathrm{v}$ Rossii [Small and medium-sized enterprises in Russia]. 2019: Stat. sb. / Rosstat. - Moscow, 2019. $-87 \mathrm{p}$.

2. Rabochaja sila, zanjatost' $\mathrm{i}$ bezrabotica $\mathrm{v}$ Rossii (po rezul'tatam vyborochnyh obsledovanij rabochej sily) [Labor force, employment and unemployment in Russia (based on the results of sample surveys of the labor force)]. Stat. sb. / Rosstat. - Moscow, 2020. - $145 \mathrm{p}$.

3. Itogi Vserossijskoj sel'skohozjajstvennoj perepisi 2016 goda: $\mathrm{v} 8 \mathrm{t}$. [The results of the AllRussian agricultural census of 2016: in 8 vol.] / Federal'naja sluzhba gos. statistiki. - Moscow: IIC «Statistika Rossii», 2018.

4. Rossijskij statisticheskij ezhegodnik [Russian Statistical Yearbook]. 2019: Stat. sb. / Rosstat. - Moscow, 2019. — 708 s.

5. Nizhegorodcev R. M., Petuhov N.A. Podhody k prognozirovaniju sprosa na regional'nyh rynkah truda [Approaches to forecasting demand in regional labor markets] // Upravlenie innovacijami - 2020: Materialy mezhdunarodnoj nauchno-prakticheskoj konferencii [Innovation Management - 2020: Materials of the international scientific and practical conference] / In R.M. Nizhegorodcev, N.P. Gorid'ko (eds.). — Novocherkassk: JuRGPU (NPI), 2020. 


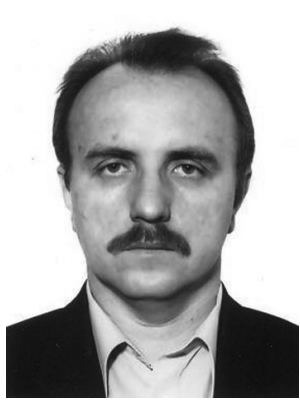

Петухов Николай Анатольевич - кандидат экономических наук, старший научный сотрудник Института проблем управления РАН. Круг научных интересов включает вопросы региональной экономики, экономики науки и образования, макроэкономики, экономического прогнозирования. Автор более 140 научных публикаций.

Petukhov Nikolay Anatolevich - Candidate of Economic Sciences, Senior Research Assistant of Institute of Control Sciences of the Russian Academy of Sciences. General interests in field of science include regional economy, economics of research and education, macroeconomics, economic forecasting. Author of more than 140 scientific publications.

117342, г. Москва, ул. Профсоюзная, 65 65 Profsoyuznaya st., 117342, Moscow, Russia E-mail: MTEK-01@mail.ru 